\title{
Alive by Meeting: A Solution to the Paradox of Meetings Based on the Pyramid of New Collaboration
}

\author{
Marco Bettoni ${ }^{1}$ and Eddie Obeng ${ }^{2}$ \\ ${ }^{1}$ Steinbeis Consulting Center Knowledge Management and Collaboration, Basel, Switzerland \\ 2Pentacle Virtual Business School, Beaconsfield, Buckinghamshire, UK \\ marco.bettoni@weknow.ch \\ Eddie Obeng@pentaclethevbs.com \\ DOI: 10.34190/EJKM.18.02.006
}

\begin{abstract}
Meetings are the activity at the centre of every organisation; they are critical. But there is a problem: most people hate them. How can we solve this so-called "paradox of meetings"? How can we avoid death by meeting? By reviewing meeting theories which help to better understand meetings, we have found support for the view that bad meetings today are primarily the consequence of unsuitable knowledge sharing and collaboration. Based on this and by applying our new understanding of collaboration as New Collaboration, we propose to look at meetings by focusing on collaborative problemsolving and to perceive collaboration in such problem-solving meetings as New Collaboration. But how do we have to interact in order to implement New Collaboration in meetings? This is where our Pyramid of New Collaboration comes in as a detailed description of the collaboration process. Our paper will first review related literature dealing with leadership, meeting theories, knowledge sharing and collaboration. Then, we will explain in detail our concept of collaboration, the process of collaboration and the Pyramid of New Collaboration with its seven layers. Finally, we will discuss the application of the Pyramid to the solution of the paradox of meetings and propose the concept of a New Collaboration Meeting.
\end{abstract}

Keywords: paradox of meetings, collaborative problem-solving, knowledge sharing, new collaboration.

\section{Introduction}

Meetings are the activity at the centre of every organisation, "one of the most ubiquitous activities in organizations" (Duffy and O'Rourke, 2015) and they are critical for success (Gordon, 2001; Lencioni, 2004; Eppler, 2016). But there is a problem: most people hate them; they complain about meetings, they try to avoid them, they arrive late, are not prepared for the agenda topics and they turn to their e-mail, Twitter and Google on their notebook in order to avoid "death by meeting" (Lencioni, 2004). The results are bad meetings, and this, in the end, leads to bad decisions.

What we have here is the so-called "paradox of meetings": on one side there is an activity which is essential for the success of an organisation at any level (board meetings, project meetings, team meetings, etc.), and on the other side there is inner capitulation, a resignation of the participants as we have come to tacitly accept that this activity was, is, and always will be bad. How can we solve this paradox? How can we become "alive by meeting" again?

First of all, we need to better understand meetings as an organisational way of interacting; we need a kind of organisational meeting theory. To this end, we will look at meeting science, a relatively new scientific domain which systematically studies meetings (Allen et. al. 2015; Olien et al. 2015); we will also consider in detail successful practical theories and best practice prescriptions - like those by Thomas Gordon (2001) and by Patrick Lencioni (2004) - as well as theories and best practices regarding meeting-related phenomena which have been proposed more recently in the book "The Complete Leader" (Obeng and Gillet, 2008), in the "Meeting Manifesto" (Eppler, 2016) and in the definition of New Collaboration (Bettoni, et al., 2018a).

By means of the SFM method (Bettoni, Bernhard and Bittel, 2013), we will introduce some order and connections among the selected claims of these theories. This will allow us to create a strong connection between meetings and collaboration. Essentially, we will propose a process view on meetings which focuses on collaborative problem-solving and perceives it as New Collaboration. This is a knowledge-based and community-oriented problem-solving method of interaction which, although unnoticed, has accompanied the rise of ICT since the beginning and today is tacitly and unconsciously emerging more and more, particularly in businesses which need to tackle the new challenges of an increasingly volatile, uncertain, complex and ambiguous world (VUCA). 
But how should people interact in order to implement New Collaboration in meetings? This is our main research question here and we plan to answer it by relying on the Pyramid of New Collaboration (Bettoni and Obeng, 2019), considered as a detailed description of the collaboration process. The Pyramid allows us to clarify: 1) the new role of knowledge sharing in supporting collaboration; 2) stages in the process of sharing knowledge; 3) how knowledge sharing is deeply grounded in space (Bettoni, et al., 2018b). This will shed new light on how to successfully interact in meetings and will enable dramatic improvements in the design, management of and participation in meetings.

Our paper is structured as follows. Following section 1, in which we have provided an overview of the research problem (paradox of meetings) and of relevance, in section 2 we will collect the state of the art and past knowledge related to the problem. Section 3 outlines the main steps of our research methodology (design science), and describes our method for constructing a solution. Section 4 describes the results of our research, a model of a meeting composed of: 1 ) a clarification of the concept of collaboration (New Collaboration); 2) the introduction of the concept of a Joint Knowledge Base; 3) a model of the stages of the collaboration process (Pyramid of New Collaboration). We will then discuss in section 5 the implications and limitations of our model as well as future work and conclude the paper by concisely stating in section 6 where we see the main aspects and value of our contribution.

\section{Literature Review}

Much of the earlier organisational research literature used meetings mostly "as a mere context for other group phenomena" (Olien et al. 2015), largely ignoring their importance as a topic of research in themselves. Of course, research on subjects which are highly relevant to meetings, such as team interactions and leadership, existed but for a long time, meetings per se have not been a topic of research in management literature (Dittrich et al. 2011; Allen et al. 2015). Rigorous, scientific analysis of meetings which is now called meeting science "started in earnest only about a decade ago" (Kello 2015). Some of the central conclusions from this new meeting science have been recently summarised as follows (Kello 2015, p. 717): 1. Huge time cost; 2. Huge financial cost; 3. Meetings are ubiquitous; 4 . Meetings are seen as unproductive; 5 . Meetings have a broad impact; 6 . Leadership is critical; 7. Participants can co-lead.

On the other hand, practitioners have long recognised the importance of meetings - for instance Thomas Gordon since the 50s or Patrick Lencioni and Eddie Obeng in the 90s - and the practice literature with experience-based guidance is correspondingly vast.

Thomas Gordon was a proponent of a participative style of leadership and management "that encourages equalitarian relationships, teamwork, cooperation, interdependence, accountability and the free flow of information" (Gordon, 2001, p.VII). His theory of meeting is implicitly contained within his leadership theory, first published in 1955. This theory was too radical for that time; later (1977), when this participative approach had become part of mainstream thinking in organisational leadership, Gordon published an updated theory which incorporates advances from studies about effective leadership which in the meantime had become available (Gordon, 2001). In this book, Gordon describes not only what makes a good leadership and why but also how to do it, the methods. This part also includes a few methods for improving meetings such as team building, distinguishing different types of meetings, a focus on problem-solving meetings, meeting evaluation, several "guidelines for making management meetings work" (Gordon, 2001, Chapter VII) and a method for "turning conflict into cooperation" (Gordon, 2001, Chapter VIII).

Patrick Lencioni, a business consulting guru, author of several best-selling books and president of The Table Group (a San Francisco Bay Area consulting firm), contends that "bad meetings start with the attitudes and approaches of the people who lead and take part in them" and that in order to "transform them into compelling, productive, and fun activities", we need to "fundamentally rethink much of the way we perceive and manage meetings" (Lencioni, 2004, p.221). In his model, Lencioni concentrates on two main problems with meetings (they are boring and ineffective), analyses the reasons and suggests two solutions (constructive conflict and multiple types of meetings).

Based on the insight that our business world is a "new world" (Obeng 1997), Eddie Obeng and Christophe Gillet (2008) have developed an innovative understanding of leadership. They claim that in our "new world": 1) the 
pace of change has become greater than our organisations' speed of learning (crossover model); and that 2) since this crossover took place, the rules for being an effective leader have changed accordingly.

Based on these two insights and drawing on over 40 years of leadership experience, teaching, client assignments and research, they have been able to specify 12 new rules (Obeng, 1997) and figured out several leadership methods which also apply to what we need to think and do differently in order to achieve good meetings. Rule 3 for example states: "Change dependence to interdependence". Interdependence is created, for example, by assigning tasks to more than one person, with reward structures which require that contributions of more than one person need to be included and by planning which focuses on the links between the activities of different people (Obeng, 1997, pp.131-132).

Some essential claims about bad and good meeting practice are summarised in the "Meeting Manifesto" (Eppler, 2016) composed by 16 statements divided into 3 sections: A) Premises (2 statements), B) Rights and duties of meeting participants (8) and C) Requests (6). For example, a premise in the first section reminds us that meetings occupy a great part of our daily worktime while a right and a duty declaration in the second section both emphasise the importance of constructive interactions; finally, in the third section, one of the statements requests top-quality interactions.

Last but not least, in good meetings interactions correspond to the new practice of collaboration which is emerging in the world of VUCA; we have called it New Collaboration and defined it as follows (Bettoni and Obeng, 2018a, p.1135): "New Collaboration is a coordinated activity between persons who interact (online or in presence) for working together at the same, single task and who, concurrently, are also mutually engaged as a community in a conscious, continuous effort to construct and maintain an underlying shared knowledge structure as a basis for accomplishing their task."

\section{Methodology}

To answer our main research question, we take a design science approach (Hevner et al. 2004; Hevner 2007) which is structured as follows. First of all, in the introduction (section 1), we have presented the problem relevance and motivation for our research topic, the so-called paradox of meetings. Secondly in the literature review (section 2), we have examined the state of the art and past knowledge in the field of our research topic. As a third step, we will now take the requirements from step 1 and use appropriately selected knowledge from step 2 to construct an innovative solution to the paradox of meeting (section 3 and 4). Evaluation, feedback and refinement of the solution proposed here will be carried out in future work.

To construct a solution, we need to introduce some order and connections amidst the claims of the meeting theories mentioned in the literature review. To this aim, we will apply the SFM method (Bettoni, Bernhard and Bittel, 2013). Its guiding principle is that, in order to find a high-quality solution, three elements (or aggregates of elements) should always be explicitly identified and connected to build a coherent triad: need, objective and solution.

We live in an increasingly volatile, uncertain, complex and ambiguous business world (VUCA) where the pace of change has overcome our organisations' speed of learning (Obeng and Gillet, 2008). And we live in a Knowledge Society where business practices and processes are increasingly becoming knowledge-intensive, in the sense that they "involve human judgment and experience, complex decision making, and very often, creativity (Davenport, 2005)" (Marjanovic and Freeze, 2012). Under these conditions, good business decisions and highquality solutions increasingly require the experience and know-how of stakeholders from interdependent people such as a group, a department or a board of directors (multidisciplinary collaboration). Thus, at any level, the need for meetings and the amount of time people spend in meetings increases and, in many cases, becomes a great part of their daily worktime (Eppler, 2016). In a meeting where two or more people are collaborating simultaneously on the same problem, the specific cost (money/hour) increases proportiately to the number of participants and makes the need for efficient interaction more compelling. Furthermore, the meeting also needs to be effective, particularly in the sense that, regardless of the short time available, the generated solutions and decisions taken must be of top-quality (Eppler, 2016).

From the previously mentioned meeting theories we have derived, in essence, three consequences: one objective and two needs (requirements) which match with the objective. The needs are: 1) interactions in 
meetings need first and foremost to be collaborative problem-solving interactions and 2) the principal function of the leader needs to be that of a facilitator of collaborative problem-solving. The objective is to greatly improve the quality of meetings, trying to make them engaging, inclusive, empowering, efficient and effective.

Both the needs and also the objective had already been recognized 40 years ago by Thomas Gordon. He suggests "to think of the principal function of a group leader as facilitating problem-solving" (Gordon, 2001, p.28) and to think of effective leaders as people "with skills in problem solving" who "need not assume full responsibility to problem-solve alone" but rather "enlist the resources of the group members to help them" (Gordon 2001:41). And for this, the leader needs meetings: "I know of no other way to build an effective management team. While they can't be avoided, most meetings certainly can be greatly improved - but not without considerable effort by the group leader" (Gordon, 2001, p.125).

Following the SFM method, we must now search for a solution which satisfies the needs and fulfils the objective which we have derived from the previous assessment, thus creating a coherent triad, a unity of need, objective and solution, which can be represented by means of a diagram called a solution map (Bettoni, Bernhard and Bittel, 2013, p. 46).

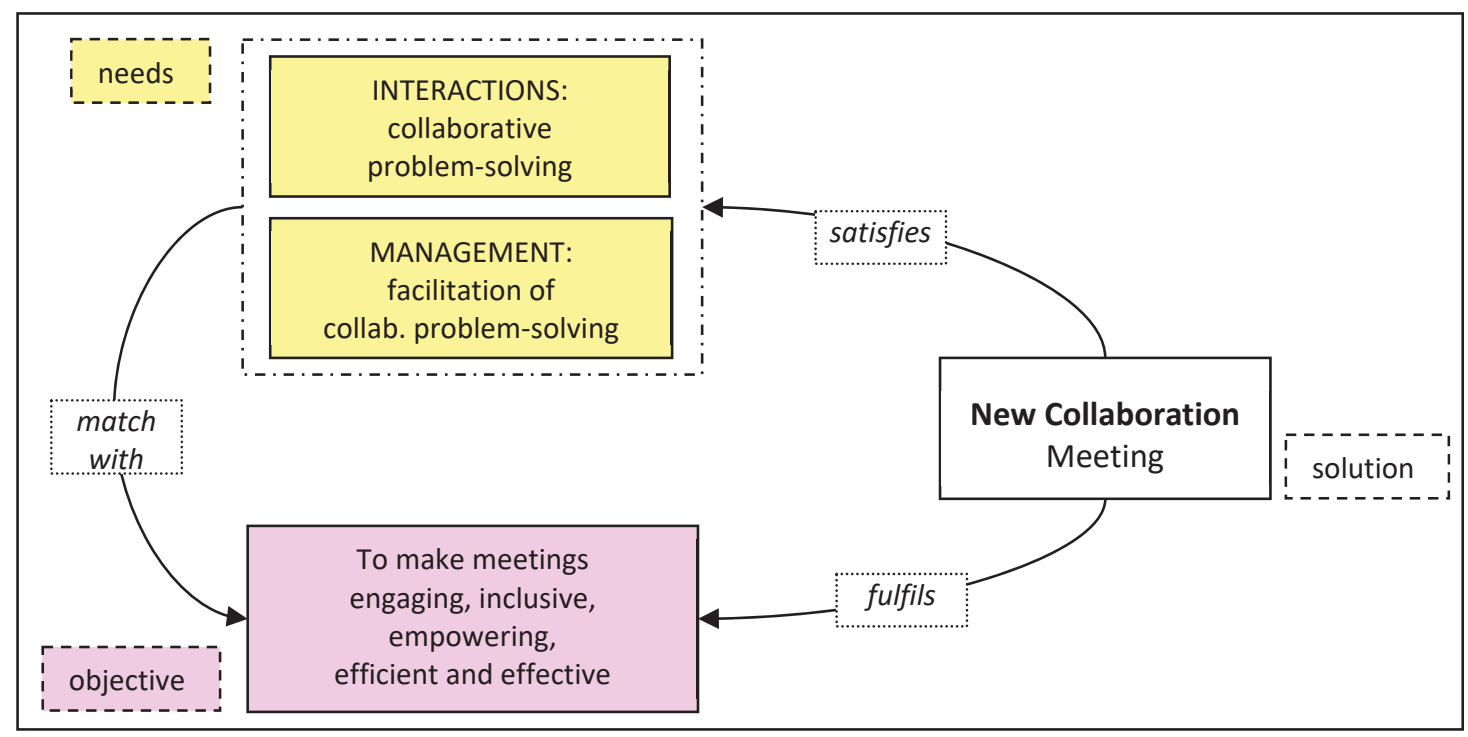

Figure 1: Solution Map "New Collaboration Meeting”

We claim (see Fig. 1) that the need for collaborative problem-solving and the need for a leader as a facilitator of collaborative problem-solving can be satisfied with a type of meeting which focuses on collaboration conceived as a knowledge-based and community-oriented problem-solving method which we have called "New Collaboration" (Bettoni, et al., 2018a). And this same type of meeting will also fulfil the objective of producing good meetings. To support these claims, we need now to shed new light on collaboration and knowledge sharing by explaining what New Collaboration is and showing how it works (section 4).

\section{Results}

Collaboration may appear to be easy but it is not! Collaboration is not easy because we do it without sufficiently understanding its complexity; and we do not try to sufficiently understand it precisely because it seems to be easy. A deadlock! Since we are not aware of being trapped in such a deadlock, no platform, no software, no artificial intelligence will ever help us to get out; we must try to reflect more deeply on collaboration and perseverate until we succeed in better understanding it. One essential aspect of New Collaboration which we should understand and take seriously (especially for online collaboration) is its relationship with knowledge sharing. Unfortunately, little is known about how collaboration and knowledge sharing actually proceed. In organisational and educational contexts, research focuses mostly either on outcomes or on "external" aspects as conditions for successful outcomes of collaboration and knowledge sharing, such as cognitive, social and emotional aspects (Järvelä, et al., 2015), corporate culture (Hernández Sanchez, et al., 2013) or interpersonal, team, individual, motivational and cultural factors (Wang and Noe, 2010). These areas of insight are useful and 
necessary but they do not explain how collaboration actually proceeds. In order to know how to design the process itself, we need to shed light on the black box and on its internal workings (see Fig. 2).

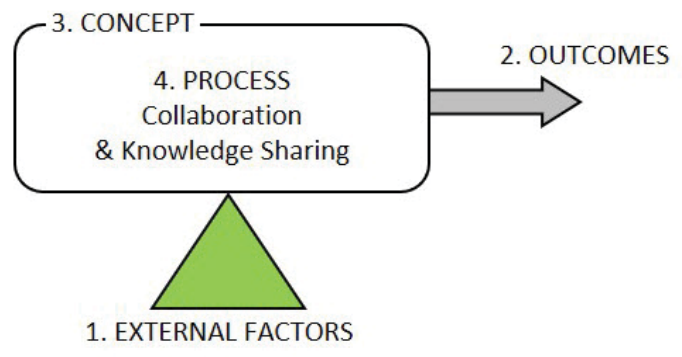

Figure 2: Four main aspects of collaboration \& knowledge sharing.

We believe that focusing on two internal aspects of collaboration and knowledge sharing, concept (what) and process (how), is of at least equal if not greater importance than studying external factors and outcomes. With our model of the inner workings of the collaboration process (Bettoni and Obeng 2019), we want to help take the complexity of the collaboration process seriously and devise ways and tools for better exploiting the potential of collaboration so that it becomes engaging, inclusive, empowering and highly effective.

\subsection{Concept of collaboration}

Before analysing the process of collaboration, it is useful to clarify our concept of collaboration, i.e. what kind of activity we are seeking to understand. Our concept of collaboration is knowledge-based and communityoriented: we call it "New Collaboration" (Bettoni, et. al., 2018a) and it is not just an abstract idea; in fact, it is already happening in practice although we are not aware of it (Bettoni, 2017; Ehmer, 2017).

In the VUCA world, successful people collaborate in a new way: they work together on a task without splitting it. And because the task is not split, the related knowledge needed during the performance of the task must also build a unit and be maintained as a unit. For this reason, new collaboration must be knowledge-based. Moreover, since keeping this task-related knowledge as a unit requires the mutual engagement of the group in a conscious, continuous effort to construct and maintain this unit as a shared knowledge structure, new collaboration must also be community-oriented (see the definition of New Collaboration at the end of section 2). This definition, which closely links collaboration and knowledge sharing, has its roots in the seminal work by Roschelle and Teasley (1995) which investigated collaborative problem solving almost 25 years ago. In their definition, "Collaboration is a coordinated ... activity that is the result of a continued attempt to construct and maintain a shared conception of a problem" (Ibid., 1995). Based on our definition of collaboration, the analysis of the process of collaboration, for example collaboration by a project team, can be split into two areas of inquiry:

- Analysing how team members interact for dealing with task T (planning, design, problem solving, etc.)

- Analysing how team members construct and maintain a shared knowledge structure relating to that task T.

For our analysis of the process of collaboration, we will again use the framework developed by Roschelle and Teasley $(1995$, p.75 ff) as a source of inspiration but while suggesting some modifications. Moreover, like Roschelle and Teasley, we also make a distinction between collaboration and cooperation. We use the term "cooperation" when working together is accomplished through a division of labour among participants whereby the task is split into parts and each person is responsible for one part (ibid., 1995, p.70).

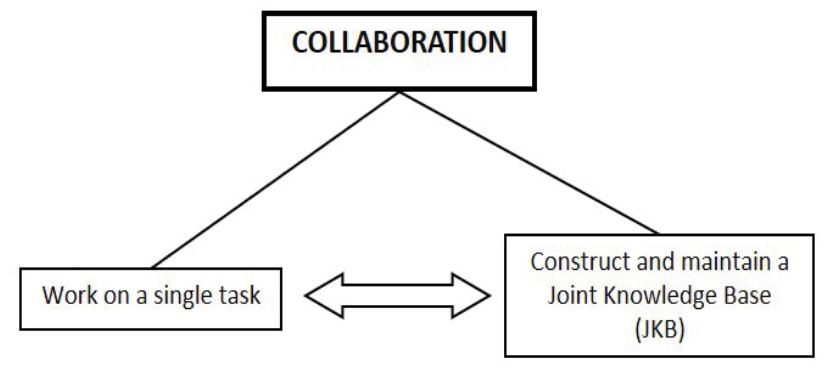

Figure 3: Concurrent, co-existing and connected activities which constitute the process of collaboration 
Collaboration is a different concept (Fig. 3): the task is not split and it remains as a single unit; each participant works on the whole task and is responsible for it as a whole. The notion of a "shared knowledge structure", which Roschelle and Teasley call "Joint Problem Space (JPS)", is central to their approach which proposes that the fundamental activity of the process of collaboration "occurs via engagement with an emergent, socially negotiated set of knowledge elements that constitute a Joint Problem Space" (ibid. 1995, p.70).

\subsection{Joint Knowledge Base (JKB)}

Because of the term "problem space", the concept of a JPS could be wrongly associated with the Artificial Intelligence concept of problem space as originally introduced by Allan Newell and Herbert Simon in their general theory of problem solving (Newell and Simon, 1972; Sarmiento and Stahl, 2008). The problem space represents the problem by means of "states of knowledge", the initial (current) state, the goal state and all possible states in-between; domain knowledge and heuristics help people navigate their way through all the possible knowledge states. This approach failed in real-world domains but contributed to highlighting the importance of task-specific, expert knowledge (Ohlsson, 2012) and to promoting the idea that intelligent systems derive their power from the specific knowledge they possess rather than from general search algorithms. As a consequence, in the 1980s Al changed its focus from search systems and general problem solvers to knowledge representation and knowledge-based systems, for example expert systems which could match human competence on a specific task (medical diagnosis, computer configuration, etc.)

In order to avoid terminological misunderstandings and against the background of our own experience with knowledge engineering and the development of expert systems (Bettoni and Bernhard, 1994; Bettoni and Fuhrer, 2001), we suggest substituting the term Joint Problem Space and introducing instead the term "Joint Knowledge Base" to indicate the shared knowledge structure which each team member constructs and maintains in his/her mind during collaboration. Collaborators interact by conversation, physical action and interaction (combinations of words and action). During these activities, each collaborator contributes to the construction of the JKB relating to the task at hand. And at the same time, the JKB functions as a basis for accomplishing the task on which the team is working (see Fig. 3) and can also be seen as an essential condition of the possibility of successful collaboration.

\subsection{The Pyramid of New Collaboration}

After having noted that collaboration is based on knowledge sharing, the question which naturally arises is "How does the process of knowledge sharing proceed?" Knowledge sharing is a complex and inherently fragile process (Roschelle and Teasley 1995:94) during which the participants need to possess specific competences which they will apply to overcome many different kinds of difficulties. Analysis of this process shows that a successful knowledge sharing experience occurs through the integration of three essential elements: cognitive presence, social presence and leading presence (Bettoni, et al., 2018b, p.170), a model inspired by the Community of Inquiry (Col) framework (Swan, Garrison and Richardson, 2009) and consistent with Barron's dual space model of collaboration which differentiates between the social and cognitive aspects of collaboration (Barron, 2003). In our model of 2018, the point of view was based on aggregation in a hierarchy of parts (or steps) required for the process. Here we want instead to consider how the components of this model enable each other as foundations or means within a hierarchy or pyramid of means and ends (Fig. 4).

This approach is inspired by the means-ends hierarchy (German: "Ziel-Mittel-Hierarchie") of Systems Engineering where it is used as a way of organising systemic objectives (Haberfellner, et al., 2002) and by the goals breakdown structure (GBS) of Project Management (Bender, 2004). Each level of the pyramid serves as both an end and a means (means-ends duality): it's an end if referred to the level below it and a means in relation to the level above it. Thus, when considering two adjacent levels, for example the upper two, you can say: we share knowledge (level 6) in order to (end) collaborate (level 7) and we collaborate by means of sharing knowledge (level 6).

We will begin the presentation of the 7 levels starting with the main end and will look for the means which are essential for reaching that main end. For this reason our presentation, instead of beginning at the base of the pyramid, will start at the top.

Level 7 - New Collaboration. The top of the Pyramid of New Collaboration consists of the process of collaboration, our ultimate goal. If we want to better exploit the potential of online collaboration for delivering successful results in the VUCA world, then we need to better understand collaboration and that is why we look 
at the foundations below it, beginning from level 6 and then going down, deeper and deeper, until we reach the ground at level 1.

Level 6 - Knowledge Sharing. Knowledge Sharing is the fundamental activity which enables New Collaboration and that is why we find it immediately below level 7. This is where collaborators construct and maintain the Joint Knowledge Base, a knowledge structure which is consistent with the previously mentioned socially negotiated set of knowledge elements as suggested by Roschelle and Teasley $(1995, \mathrm{p} .70)$. But how do they do this? What is required? To answer these questions, we move to level 5.

Level 5 - Negotiation of Meaning. Because shared knowledge requires socially negotiated meanings, the means which most directly contributes to the end of knowledge sharing is that of negotiation of meaning, one of the two main components of cognitive presence. This is therefore level 5 of the pyramid. Negotiation of meaning enables the creation of a socially negotiated JKB. Negotiation of meaning within a group or community is a process comprising participation and reification (Wenger, 1998). Wenger's model highlights the importance of considering the experience of meaning as a unity of two distinct elements which are tightly interwoven but distinct; participation refers to a process of taking part with others in some activity and recognising ourselves in each other, whereas reification according to Wenger $(1988$, p.58) refers to the process of giving form to our experiences by producing related objects.

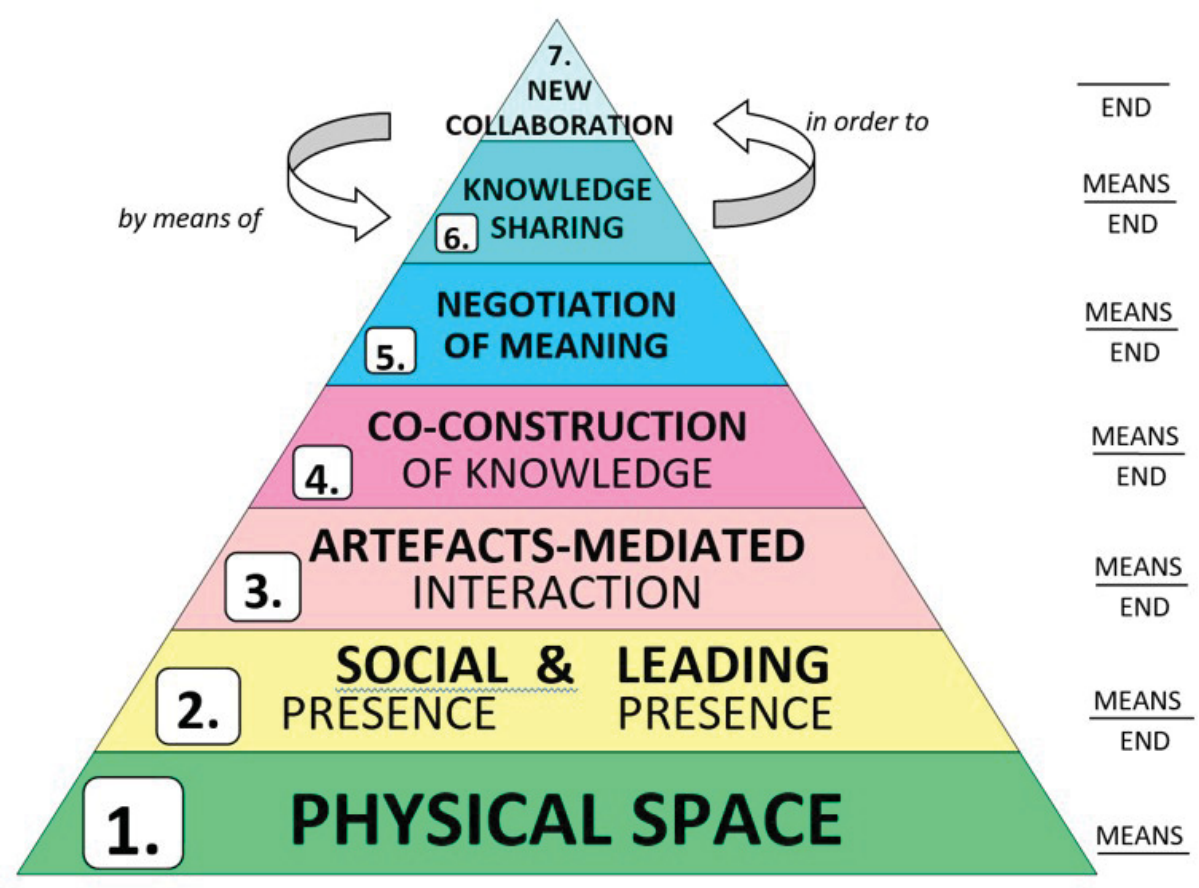

Figure 4: The Pyramid of New Collaboration (PNK)

Level 4 - Co-construction of Knowledge. Given this model of negotiation of meaning, it follows that to determine the levels of the pyramid underlying level 5, we need to find a means for implementing participation and reification as ends. Participation must be about something, some content, ideas, proposals; and reification also must be of something. So, what we need here in the first place is to produce relevant content, hence to be creative and skilled in constructing (producing or modifying) knowledge. Thus, level 4 of the pyramid is constituted through the co-construction of knowledge, the second main component of cognitive presence. This level comprises skills such as: (a) shared language, (b) shared content / storage, (c) co-planning, (d) co-solving, (e) co-writing (Bettoni, et al., 2018a, p.1137).

Level 3 - Artefacts-Mediated Interaction. What could be a good way to make the co-construction of knowledge successful? In their collaboration research, Roschelle and Teasley (1995, p.76) mention language, physical action and combinations of words and actions as three types of general activities which constitute the process of collaboration. The idea is that collaborators do not simply talk; they also need to do something physically. In knowledge work, this opportunity could be provided by a computer-based environment, like for example the direct manipulation graphical simulation environment called "Envisioning Machine" used by Roschelle and Teasley $(1995$, p.71 ff). 
A simpler and very generally applicable way of making a physical interaction happen within a group of knowledge workers (breakout group or plenary group) is the Metaplan technique (Schnelle, 1978) which uses a pin board (a panel) and cards as artefacts for mediating the interaction of the team which is co-constructing knowledge. Collaborators meet at a board which can be blank or structured (see Fig. 5) and which can hold cards (with text or images); they interact by first writing their ideas on the cards, then placing them on the panel and furthermore by organising the cards into clusters, by pointing to items and asking questions or by explaining their own ideas. All these modes and means of interaction provide resources which make knowledge sharing possible (enable) and mediate collaboration. Thus, artefacts-mediated interaction becomes level 4 of our pyramid.

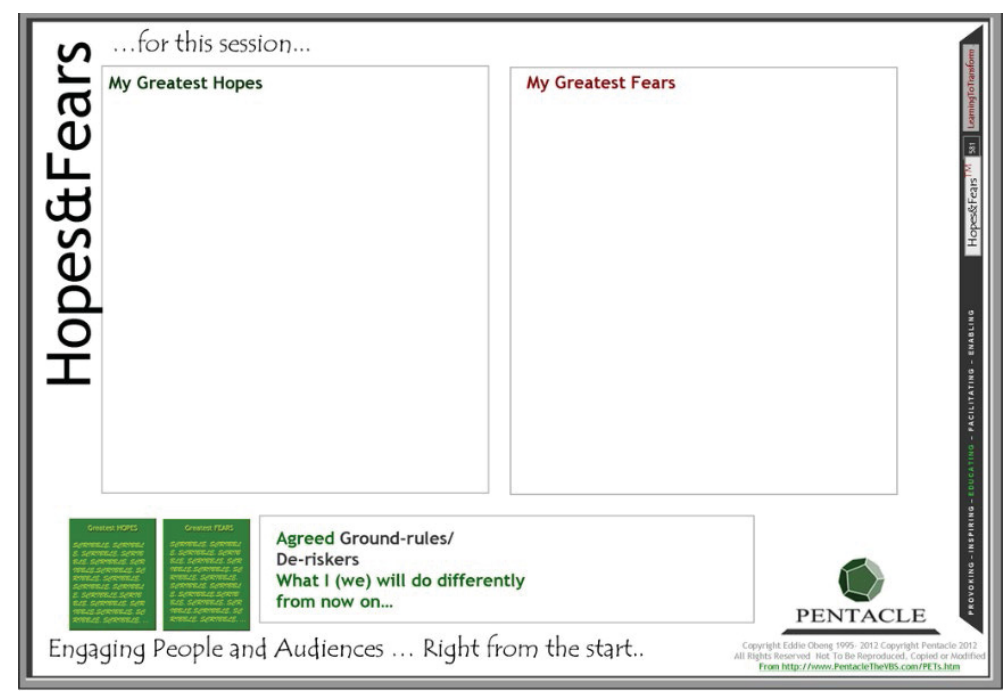

Figure 5. Artefact-mediated interaction: pin board (panel) called "Hopes and Fears" ㄷ Pentacle

Level 2 - Social Presence \& Leadership Presence. Now we come to the two lower levels of the pyramid, those which provide a stable grounding to the whole building. What happens when people interact at a pin board and what could be a good foundation for making their panel interaction successful? In our model, this is provided by leadership presence and social presence (Bettoni, et al., 2018b). Social presence is defined as the extent to which the participants of the collaboration succeed in projecting their personal characteristics onto the group (team, community), thereby presenting themselves to the other participants as "real people". They do this mainly by expressing emotions (closeness, humour, self-disclosure), by open communication (mutual awareness, recognition) and by contributing to group cohesion (empathy, participation). Leading presence is defined as the design, facilitation and support of the cognitive and social presence (of the related processes) for achieving personally meaningful and organisationally worthwhile collaborative outcomes.

Level 1 - Physical Space. Finally, the basis of our pyramid is constituted by physical space (real or virtual), simply conceived as "the three-dimensional extent in which objects and events have relative position and direction" (Encyclopaedia Britannica, 2004). The message here is that collaboration must happen in space and must use space as its most fundamental resource (Bettoni and Obeng, 2016). Why?

First, because of the role which space plays in cognitive presence (see level 4 and level 5). At the beginning of his theory of mental activity, Kant explains: "Space is a necessary a priori mental construct, which underlies all outer perceptions (Anschauungen)" (Kant, 1787, B38) and knowing, he subsequently adds, always requires a combination of perception and conception (ibid. B74). Thus, space will be contained in any knowledge item and consequently also in any human thought.

Second, because space plays an essential role in social presence. Recently Kim et al. (2014) emphasised the importance of the affordance for pointing (the gesture specifying a direction from a person's body and connecting it with a distant item) when collaborating in a shared space. Expressing emotions, open communication and group cohesion are three components of social presence which are closely related to space in the sense of "what connects and separates" (de Michelis, 2016) the persons involved. This means that space is essential as a medium which enables social presence. 
Last but not least, collaboration must happen in space because space plays a role in leading presence. The leader of a meeting has to determine how participants will interact in space so that both cognitive and social presence will be suitably supported and the work will be accomplished effectively and efficiently.

\section{Discussion}

By following the guidelines given by the Pyramid of New Collaboration, a meeting changes: it becomes a knowledge-based, community-oriented, collaborative event with a problem-solving core which we call a New Collaboration Meeting. This is the main implication of our model.

Our approach implies furthermore that, in order to properly start a New Collaboration Meeting, facilitate it efficiently and effectively and take it to a successful completion, it is central to understand its knowledge-related aspects. And this is exactly where our model of a Joint Knowledge Base (JKB) presented in section 4.2 and the Pyramid of New Collaboration presented in section 4.3 provide support. On the contrary, failure to understand the knowledge-related aspects of a meeting process is one of the root causes of bad meetings.

Since a knowledge base must be built and maintained during the meeting, another main implication of our model is that several activities connected in closed (control) loops are required: 1 ) introducing new elements (through assimilation or accommodation); 2) modifying existing elements when divergence arises during collaboration; 3 ) detecting divergence by monitoring ongoing interpretations of knowledge elements and comparing them with the intended interpretations to determine whether these fit; 4) last but not least, rectifying intended interpretations where there are conflicts (meanings do not fit).

A further implication is that we need to explain the relationship between the knowledge base of the meeting and the individual attendees. Inspired by constructivist knowledge theory (von Glasersfeld 1995, Bettoni 2005), we suggest the view that each meeting participant builds and maintains his/her own knowledge base. Thus, in the course of the meeting, we have as many knowledge bases under development as there are participants. There is no single, integrated knowledge base that grows outside the individual meeting attendees. But the overall shared goal of solving the same shared problem with the other attendees leads to the emergence of areas which mutually converge (and resonate) within the individual knowledge bases. It is within these convergent areas that knowledge is shared. But since meanings do not necessarily overlap or match across all the individual knowledge bases in these individual areas, it would be more appropriate to speak of taken-asshared rather than shared knowledge. The notion of a taken-as-shared knowledge or meaning implies that individual meanings fit for the purposes at hand and do not require that they match (Cobb, 2000, p.166). It is in this sense that we speak of a "joint" knowledge base: the JKB is the collection of those knowledge elements which constitute a unity because their meanings converge and fit across group activities and enable meaningful conversation in relation to the purposes which emerge step by step during collaboration on a shared problem.

Our answer to the question "how should people interact in order to implement New Collaboration in meetings" has some limitations which will need to be well investigated in the evaluation of this research and lead to modifications in future work. First of all, our concept of collaboration is a little too open; for instance, what does it mean in a meeting that "each participant works on the whole task"? Should everybody work on every topic? And if this is not the case, where are the boundaries? We will need to extend the definition and make it more concrete. Secondly, the pyramid as a system may seem much too static. What happens for instance when level 1 , the physical space, is missing or not good enough? Will then the whole building crash? How will the knowledge processes be affected? We will need to better clarify the pyramid system from the point of view of the relationships between the different levels, both static and dynamic relationships. Last but not least, the stages of the collaboration process will probably require customisation depending of different types of meetings in which the model will be applied. This refinement will be important for making it easier to apply the model in a variety of meeting types.

\section{Conclusion}

Meetings are too often bad, but there is nothing inherent in them that makes them so. They are bad only when the leader does not facilitate them properly and the participants do not contribute in a proper way. Proper facilitation and proper contribution require a new understanding of the needs of a meeting in the VUCA world: 1 ) interactions need to be collaborative problem-solving activities; 2 ) the management needs to be a facilitation of collaborative problem-solving. 
Looks like nothing new but why then are meetings still bad? Because collaboration seems to be easy but it is not! The Pyramid described in this paper can help to take the complexity of the process of collaboration seriously, to understand its inner workings and on this basis, to devise ways and tools for making meetings good: engaging, inclusive, empowering, efficient and effective.

First of all, participants of the meeting should continually attempt to construct and maintain a Joint Knowledge Base (JKB), an emergent taken-as-shared knowledge structure as a basis for accomplishing the shared problemsolving task. Secondly, since the knowledge elements of the JKB must be socially negotiated, constructing the JKB requires engagement in a process of negotiation of meaning, constituted by two highly interwoven activities: participation and reification.

Participation must be about something and reification must be of something: knowledge. The extent to which meeting participants succeed in negotiating meaning and co-constructing knowledge, the so-called cognitive presence, can be increased if they do not simply talk (language), they also need to engage in some physical action and interaction (combination of words and actions), a requirement which can easily be implemented by means of some artefact-mediated interaction, like the Metaplan technique. But the artefact itself is just an opportunity, a boundary object (Wenger, 1998). Making the most of it requires two types of resources and activities: social presence and leading presence.

Finally, since physical space plays an essential role in enabling cognitive, social and leading presence, the foundation of the whole pyramid of collaboration is constituted by physical space. To achieve good problemsolving meetings in the VUCA world, the required collaboration must happen in space (real or virtual) and must make use of space as its most fundamental resource.

\section{References}

Allen, J.A., Lehmann-Willenbrock, N. and Rogelberg, S.G. (eds.) 2015. The Cambridge Handbook of Meeting Science. Cambridge: Cambridge University Press.

Barron, B., 2003. When smart groups fail. Journal of The Learning Sciences, 12 (3), pp. 307-359.

Bender, M. B., 2004. Setting Goals and Expectations. The How-to Project Manage Series. College Station (TX): Virtualbookworm Press.

Bettoni, M., and Obeng, E., 2019. The Pyramid Principle of New Collaboration: Inner Workings of the Process of Collaboration. In: E. Tomé, F. Cesario and R. Reis Soares, eds. 2019. Proc. of the 20th European Conference on Knowledge Management (ECKM 2019), Universidade Europeia de Lisboa, Lisbon, Portugal, 5-6,9.2019, Vol. 1, pp.122-131.

Bettoni, M., Bernhard, W., Bittel, N. and Mirata, V., 2018a. The Art of New Collaboration: Three Secrets.In: E. Bolisani, E. Di Maria and E. Scarso, eds. 2019. Proc. of the 19th European Conference on Knowledge Management (ECKM 2018), University of Padua, Italy, 6-7 September 2018, Vol. 2, pp. 1133-1141.

Bettoni, M., Obeng, E., Bernhard, W., Bittel N. and Mirata, V., 2018b. Online Group Learning is Deeply Grounded in Shared Knowledge and Space. In: A. Volungeviciene and A. Szúcs, eds. 2018. Proc. of the EDEN 2018 Annual Conference, Genoa, Italy, 17-20 June 2018, pp. 169-177.

Bettoni, M., 2017. E-Collaboration: So arbeiten wir in Zukunft. WebConference New Work, HRnetworx, 12.9.2017, 9:1510:00. [online] available at <https://www.youtube.com/watch?v=57mdaW3apRM>

Bettoni, M., Obeng, E., Bernhard, W., Bittel N. and Mirata, V., 2017. The Importance of Space in Knowledge Sharing Online: The QUBE Approach. In: F. Marimon, M. Mas-Machuca, J. Berbegal-Mirabent and R. Bastida, eds., 2017. Proc. of the 18th European Conference on Knowledge Management, ECKM 2017, Universitat Internacional de Catalunya, Barcelona, Spain, 7-8 September 2017, Vol. 1, pp. 122-129.

Bettoni, M. and Obeng, E., 2016. 3D E-Learning for Collaboration. In: J. Pauschenwein \& J. Weinzödl, Hrsg. 2016. ELearning: Warum nicht? Eine kritische Auseinandersetzung mit Methoden und Werkzeuge. 15. E-Learning Tag der FH JOANNEUM, 15.9.2016, Graz: ZML - Innovative Lernszenarien (FH JOANNEUM), pp. 64-70.

Bettoni, M., Bernhard, W, and Bittel, N., 2013. Collaborative Solutions Quick\&Clean: The SFM Method. In: B. Janiūnaitė \& M. Petraite, eds. 2013. Proceedings of the 14th European Conference on Knowledge Management ECKM 2013. Sonning Common (UK): Academic Conferences and Publishing International Limited (acpi), vol. 1, pp.44-51.

Bettoni, M., 2005. Community Interactions and the Logic of Experience. In: Proc. C\&T 2005 -1st Intern. Workshop on Communities and Technologies from a Constructivist Point of View, 13.6.2005 Milano, Italy.

Bettoni, M. and Fuhrer, G., 2001. The First Tax Return Assessment Expert System in Switzerland. Challenges and Solutions. In: P. Miranda, B. Sharp, A. Pakstas and J. Filipe, eds. 2001. Proc. of the Third Intern. Conf. on Enterprise Information Systems, ICEIS 2001, Setùbal, Portugal, July 6-10. Setùbal, ICEIS Press, Vol. 1, pp.391-396.

Bettoni, M. and Bernhard, W., 1994. MASTER: A Knowledge-based Assistant for Speeding Up Simulation Projects. In: J. Liebowitz, ed., 1994. Proc. $2^{\text {nd }}$ World Congress on Expert Systems, Estoril, Portugal, January 10-14, 1994, MacMillan New Media, CD, Cambridge. 
Davenport, T., 2005. Thinking for a Living, Boston, MA: Harvard Business School Press.

De Michelis, G., 2016. Why Knowledge is Linked to Space. In: A. Cusinato \& A. Philippopoulos-Mihalopoulos, eds., 2016, Knowledge-creating Milieus in Europe. Firms, Cities, Territories. Berlin: Springer-Verlag.

Dittrich, K., Guerard, S., and Seidl, D. N. 2011. Meetings in the Strategy Process. Toward an Integrative Framework. Annual Meeting of the Academy of Management. San Antonio, Textas, USA.

Duffy, M. F. and O’Rourke, B. K., 2015. A Systemic View of Meetings. Windows on Organization Collective Minding. In: J. A. Allen, N. Lehmann-Willenbrock and S. G. Rogelberg (eds.) The Cambridge Handbook of Meeting Science. Cambridge: Cambridge University Press.

Ehmer, S., 2017. Kollaboration - Was Führung dazu wissen muss, ProjektMagazin 2017(13).

Encyclopaedia Britannica, 2004. Space. Physics and Metaphysics. Encyclopaedia Britannica Online. [online] Available at <https://www.britannica.com/science/space-physics-and-metaphysics>

Eppler, M. J., 2016. Meeting-Manifest für das 21. Jahrhundert, OrganisationsEntwicklung, 35 (4), pp.4-5.

Gordon, T., 2001. Leader Effectiveness Training. Proven Skills for Leading Today's Business into Tomorrow. Berkeley, CA: Berkeley Publishing Group.

Haberfellner, R. et al., 2002. Systems Engineering, Methodik und Praxis. Zürich: Verlag Industrielle Organisation, 11. Auflage.

Hernández Sánchez, J., Hernández Sánchez, Y., Collado-Ruiza, D. and Cebrián-Tarrasóna, D., 2013. Knowledge Creating and Sharing Corporate Culture Framework. Procedia, Social and Behavioral Sciences 2013(74), pp.388-397.

Hevner, A.R., March, S.T., Park, J. and Ram, S., 2004. Design Science in Information Systems Research, MIS Quarterly, 28(1), pp. 75-105.

Hevner, A.R. 2007. A Three Cycle View of Design Science Research. Scandinavian Journal of Information Systems, Vol. 19, No. 2, pp. 87-92.

Kant, I., 1787. Critique of pure reason. Translated by N.K. Smith, 1965. New York: St. Martin's.

Kello, J. E. 2015. The Science and Practice of Workplace Meetings. In: J. A. Allen, N. Lehmann-Willenbrock and S. G. Rogelberg (eds.) The Cambridge Handbook of Meeting Science. Cambridge: Cambridge University Press.

Kim, S., Lee, G., Sakata, N., Billinghurst, M., 2014. Improving co-presence with augmented visual communication cues for sharing experience through video conference. In: 2014 IEEE International Symposium on Mixed and Augmented Reality (ISMAR). pp. 83-92.

Järvelä, S., Kirschner, P. A., Panadero, E., Malmberg, J., Phielix, C., Jaspers, J., Koivuniemi, M. and Järvenoja, H., 2015. Enhancing Socially Shared Regulation in Collaborative Learning Groups: Designing for CSCL Regulation Tools. Education Tech Research Dev, pp. 63-125.

Lencioni, P., 2004. Death by Meeting. A Leadership Fable about Solving the Most Painful Problem in Business. San Francisco: Jossey-Bass.

Marjanovic, O. and Freeze, R., 2012. Knowledge-Intensive Business Process: Deriving a Sustainable Competitive Advantage through Business Process Management and Knowledge Management Integration. Knowledge and Process Management, 19, pp. 180-188.

Obeng, E. and Gillet, Ch., 2008. The Complete Leader. How to Lead to Results. Beaconsfield: PentacleWorks.

Obeng, E., 1997. New Rules for the New World. Cautionary Tales for the New World Manager. Oxford: Capstone.

Ohlsson, S., 2012. The Problems with Problem Solving: Reflections on the Rise, Current Status, and Possible Future of a Cognitive Research Paradigm. The Journal of Problem Solving, 5(1), pp.101-128.

Olien, J. L., Rogelberg, S. G., Lehmann-Willenbrock, N. and Allen, J. A., 2015. Exploring Meeting Science. Key Questions and Answers. In: J. A. Allen, N. Lehmann-Willenbrock and S. G. Rogelberg (eds.) The Cambridge Handbook of Meeting Science. Cambridge: Cambridge University Press.

E. Schnelle, Hrsg., 1978. Neue Wege der Kommunikation. Spielregeln, Arbeitstechniken und Anwendungsfälle der Metaplan-Methode". Veröffentlichungen der Stiftung Gesellschaft und Unternehmen (in German). Königstein/Ts.: Peter Hanstein Verlag. Heft 10.

Sarmiento, J.W. and Stahl, G., 2008. Extending the joint problem space: time and sequence as essential features of knowledge building. In: Proc. 8th International Conference for the Learning Sciences, Utrecht - Vol. 2 (ICLS'08) International Society of the Learning Sciences, pp. 295-302.

Swan, K., Garrison, D. R., and Richardson, J., 2009. A Constructivist Approach to Online Learning: The Community of Inquiry Framework. In: C. R. Payne, ed., Information technology and constructivism in higher education: Progressive learning frameworks. Hershey, PA: IGI Global, pp.43-57.

Von Glasersfeld, E. 1995. Radical Constructivism. A Way of Knowing and Learning. London: Falmer.

Wang, S. and Noe, R.A., 2010. Knowledge sharing: A review and directions for future research. Human Resource Management Review, 2010(20), pp.115-131.

Wenger, E., 1998. Communities of practice: Learning, meaning and identity. Cambridge, UK: Cambridge University Press. 